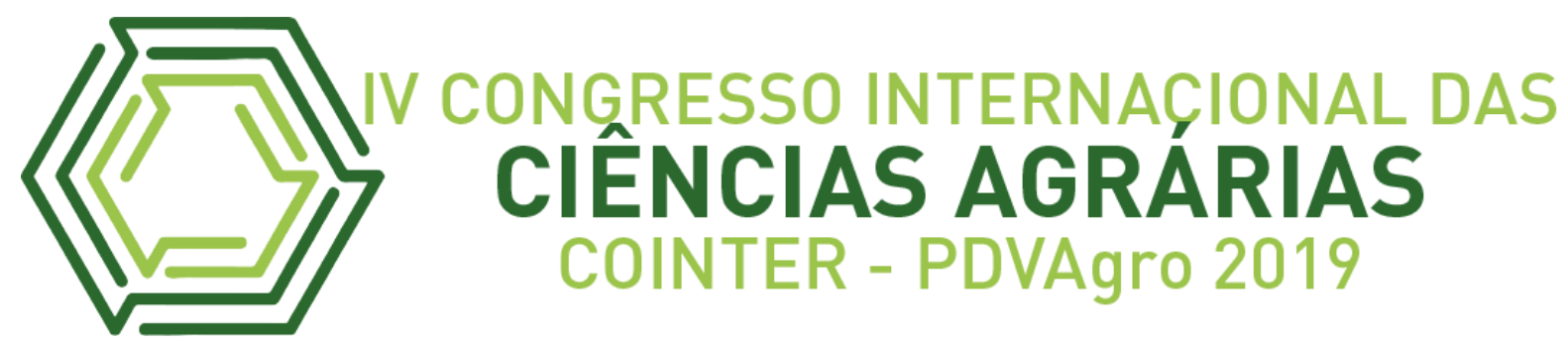

\title{
O USO DO PÓ DE ROCHA DA PEDRA CARIRI NO CRESCIMENTO INICIAL DE MUDAS DE PAU D'ARCO (Handroanthus impetiginosus (Mart. ex DC.))IMPLANTADAS EM ÁREAS DEGRADADAS
}

EL USO DE POLVO DE ROCA DE PIEDRA CARIRI EN EL CRECIMIENTO INICIAL DE LAS PLANTAS DE PAU D'ARCO (Handroanthus impetiginosus (Mart. ex DC.))IMPLANTADAS EN ZONAS DEGRADADAS

\section{THE USE OF CARIRI STONE ROCK POWDER IN THE INITIAL GROWTH OF PAU D'ARCO (Handroanthus impetiginosus (Mart. ex DC.))SEEDLINGS IMPLANTED IN DEGRADED AREAS}

\section{Apresentação: Comunicação Oral}

Ana Cláudia do Nascimento Silva ${ }^{1}$, Sayonara Rejane Lima Araújo ${ }_{2}^{2}$ Luiz Francinélio Cavalcante Júnior $^{3}$, Josefa Maria Francieli da Silva ${ }^{4}$ Sebastião Cavalcante de Sousa ${ }^{5}$.

Autor Principal ${ }^{1}$; Coautor $^{2}$; Coautor $^{3}$ Coautor $^{4}$; Orientador $^{5}$

DOI: https://doi.org/10.31692/2526-7701.IVCOINTERPDVAgro.2019.0109

\footnotetext{
${ }^{1}$ Agronomia, Universidade Federal do Cariri, a.cn2886@hotmail.com

${ }^{2}$ Agronomia Universidade Federal do Cariri, araujo.sayonara@gmail.com

${ }^{3}$ Agronomia, Faculdade de Ciências Agrárias de Araripina, luizfrancinelio@gmail.com

${ }^{4}$ Agronomia, Universidade Federal do Cariri, francielisilva39@yahoo.com.br

${ }^{5}$ Professor Adjunto, Universidade Federal do Cariri, Crato (CE), E-mail: sebastiao.sousa@ ufca.edu.br
} 


\section{Resumo}

O semiárido brasileiro vem sofrendo continua degradação ambiental, principalmente com o uso inadequado do solo, o que tem acarretado perdas consideráveis de produção nos diversos sistemas agrícolas no referido bioma. O presente estudo objetivou aplicar práticas de conservação do solo na implantação de sistemas agroflorestais no semiárido nordestino. As práticas de manejo avaliadas foram terraço de base estreita, pó da rocha pedra cariri em mudas de pau d'arco Handroanthus impetiginosus (Mart. ex DC.) Mattos. O experimento foi conduzido na comunidade de Triunfo, Nova Olinda- CE entre o período de março a junho de 2019 em delineamento inteiramente casualizado, com 5 estações envolvendo 4 terraços de base estreita, 4 tratamentos de pó de rocha: T1- testemunha, T2- 50g de pó amarelo, T3- 50g de pó cinza, T4- 25g de pó amarelo + 25g de pó cinza. A análise estatística foi realizada no programa SPSS Statistics. A análise do período hídrico apresentou $463 \mathrm{~mm}$ de chuvas e 3 períodos de déficits hídricos. A estação 3 entre os terraços 2 e 3 apresentou melhor crescimento no diâmetro do caule de plantas. A rochagem não apresentou diferenças significativas entre os tratamentos mas na estação 3 o pó cinza apresentou melhor resultado. $\mathrm{O}$ terraço de base estreita apresentou resultado imediato no controle da erosão hídrica e na perda de água por escoamento superficial.

Palavras-Chave: Agroflorestas, Manejo de solo, Terraceamento

\section{Resumen}

La región semiárida brasileña ha sufrido una degradación ambiental continua, principalmente debido al uso inadecuado del suelo, lo que ha causado considerables pérdidas de producción en los diversos sistemas agrícolas en el bioma referido. El presente estudio tuvo como objetivo aplicar prácticas de conservación del suelo en la implantación de sistemas agroforestales en el semiárido del noreste. Las prácticas de manejo evaluadas fueron terrazas de base angosta, polvo de roca roca cariri en plántulas de pau d'arco Handroanthus impetiginosus (Mart. Ex DC.) Mattos. El experimento se realizó en la comunidad de Triunfo, Nova Olinda-CE entre marzo y junio de 2019 en un diseño completamente al azar, con 5 estaciones que involucran 4 terrazas de base angostas, 4 tratamientos de polvo de roca: control T1, T2- 50 g de polvo amarillo, T3- $50 \mathrm{~g}$ de polvo gris, T4- $25 \mathrm{~g}$ de polvo amarillo $+25 \mathrm{~g}$ de polvo gris. El análisis estadístico se realizó con el programa SPSS Statistics. El análisis del período de agua presentó $463 \mathrm{~mm}$ de lluvia y 3 períodos de déficit hídrico. La temporada 3 entre las terrazas 2 y 3 mostró un mejor crecimiento en el diámetro del tallo de la planta. La roca no mostró diferencias significativas entre tratamientos, pero en la temporada 3 el polvo 
gris mostró mejores resultados. La estrecha terraza de la base mostró un resultado inmediato en el control de la erosión y la pérdida de agua por la escorrentía.

Palabras Clave:Agroforestería, gestión de suelos, terrazas

\begin{abstract}
The brazilian semi-arid region has suffered continuous environmental degradation, mainly due to the inadequate use of the soil, which has caused considerable losses of production in the various agricultural systems in this biome. The present study aimed to apply soil conservation practices in the implantation of agroforestry systems in the northeastern semiarid region. The management practices evaluated were narrow base terrace, rock cariri stone powder in pau d'arco (Handroanthus impetiginosus (Mart. ex DC.)) Mattos. The experiment was conducted in the community of Triunfo, Nova Olinda-CE between march and june of 2019 in a completely randomized design, with 5 stations involving 4 terraces of narrow base, 4 treatments of rock dust: T1- control, T2- 50g of yellow powder, T3- 50g of gray powder, T4- $25 \mathrm{~g}$ of yellow powder $+25 \mathrm{~g}$ of gray powder. Statistical analysis was performed in the SPSS Statistics program. The analysis of the water period showed $463 \mathrm{~mm}$ of rainfall and 3 periods of water deficits. Station 3 between terraces 2 and 3 showed a better growth in the stem diameter of plants. The rock powder did not present significant differences among the treatments but in season 3 the gray powder presented better results. The narrow base terrace presented an immediate result in the control of water erosion and loss of water by runoff.
\end{abstract}

Keywords: Agroforests, Soil management, Terrace

\title{
Introdução
}

O semiárido brasileiro abrange 1.262 municípios, $1.128 .697 \mathrm{Km}^{2}$ de área e 27.870.241 habitantes, sendo uma das regiões tropicais mais populosas dessa faixa climática, a vegetação predominantemente é a caatinga, composta de uma variedade de espécies arbóreas e arbustivas e, embora apresente alta diversidade biológica, vem suportando contínua degradação (GONZAGA et al., 2003).

A degradação ambiental é o resultado de um conjunto de ações e processos impactantes sobre o ambiente que, não respeitando a sua capacidade de suporte e/ou a sua aptidão, acarreta o comprometimento dos recursos naturais e, consequentemente, a qualidade 
de vida (LIMA, 1997). A agricultura é uma atividade que provoca essa degradação, pois à medida que é realizada sem critérios técnicos e sem práticas agronômicas adequadas pode trazer danos para o meio ambiente.

A utilização de espécies nativas para reflorestamento ou recomposição florística de áreas degradadas é de grande importância para reduzir o impacto ambiental gerado pela degradação e conservar a biodiversidade dessas áreas (CALDEIRA et al., 2008).

A erosão dos solos é um extenso, sério e crescente problema no Brasil, onde se perdem a cada ano milhões de toneladas de solo agrícola, devido à erosão e ao uso inadequado do solo (GRIEBELER, 2000).

A rochagem é uma prática importante para uma agricultura ecologicamente sustentável, por não ser um fertilizante industrializado. $\mathrm{O}$ pó de rocha possui um baixo valor agregado, sendo um insumo acessível tanto para o pequeno quanto para o grande produtor. (FERNANDES et al., 2010).

Diante do exposto, o presente estudo teve como objetivo avaliar a eficiência do pó de rocha da pedra cariri sobre o crescimento inicial de uma agrofloresta, implantada com pau d'arco (Handroanthus impetiginosus (Mart. ex DC.) Mattos), conduzida em terraços de base estreita.

\section{Fundamentação Teórica}

Semiárido Brasileiro

O semiárido é um bioma que está presente em grande parte da região nordeste brasileira, o qual faz parte da vida dos nordestinos. Ele ainda é caracterizado pela aridez do clima e deficiência hídrica. Não se pode negar a existência do déficit hídrico, no entanto, isso não quer dizer, necessariamente, falta de chuvas, pois temos o semiárido mais chuvoso do planeta (MALVEZZI, 2007). "No semiárido brasileiro a evaporação é cerca de 3.000 mm/ano, três vezes maior do que a precipitação. Logo, o jeito de agasalhar a água de chuva é fundamental para aproveitá-la” (MALVEZZI, 2007, p. 10). 
O semiárido está entrelaçado com o Nordeste, através da sua história, desde a sua criação. Silva (2006) diz que a primeira delimitação do semiárido foi estabelecida em 1936, com o polígono das secas, mas somente em 1988 foi que a área denominada semiárido passou a ter um conceito técnico, conforme menciona o mesmo (2006, p. 16):

O conceito técnico de Semi-árido é decorrente de uma norma da Constituição Brasileira de 1988, mas, precisamente do seu Artigo 159, que instituiu o Fundo Constitucional de Financiamento do Nordeste (FNA). A norma constitucional manda aplicar no Semi-árido, 50\% dos recursos destinados ao fundo. A Lei 7.827, de 27 de setembro de 1989, regulamentando a Constituição Federal, define como Semiárido a região inserida na área de atuação da Sudene, com precipitação pluviométrica média anual igual ou inferior a $800 \mathrm{~mm}$.

A precipitação pluviométrica do semiárido brasileiro é marcada pela variabilidade no espaço e no tempo, que, associada aos baixos totais anuais sobre a região, resulta na frequente ocorrência de dias sem chuva, ou seja, veranicos, e consequentemente, em eventos de "seca" (ZUFFO, 2019).

Degradação ambiental

De acordo com a Política Nacional do Meio Ambiente (Lei Federal $n^{\circ}$ 6.938/81), degradação ambiental é qualquer "alteração adversa das características do meio ambiente" (art. $3^{\circ}$, inciso II), neste sentido observa-se que trata de um "conceito amplo que abrange vários casos como prejuízo ao meio ambiente, ao bem-estar das pessoas, à biosfera, etc" (LIMA et al., 2004).

A degradação dos solos é a "alteração das propriedades do solo que acarreta efeitos negativos sobre uma ou várias funções do solo, a saúde humana ou o meio ambiente" (ISO 11074- 1: 1996 apud SÁNCHES, 2006, p. 16). Os principais fatores da degradação do solo, o desmatamento, a agricultura, o superpastoreio, entre outros, constituindo em prejuízos econômicos, sociais e ambientais. 
Recuperação de áreas degradadas

Áreas degradadas são definidas como ecossistemas que sofreram distúrbios que, pela amplitude, não têm a capacidade de se recuperarem até voltarem ao seu estado de equilíbrio dinâmico, perdendo a aptidão de se reorganizar e manter na essência as mesmas funções, estrutura e sustentabilidade (RODRIGUES et al., 2009; CURY; CARVALHO JR, 2011).

As atividades antrópicas, quando desenvolvidas desordenadamente, sem tomar em consideração aspectos conservacionistas, acarretam a degradação dos ecossistemas (VALCARCEL; SILVA, 1997).Nesses casos, em que a recuperação natural é muito lenta ou inexistente, a intervenção humana faz-se necessária, a fim de estabilizar e reverter os processos de degradação, estimulando e direcionando a sucessão natural (KAGEYAMA et al., 2003).

A recuperação de áreas degradadas (RAD) tem por objetivo permitir que o espaço danificado ou destruído volte a contar com recursos bióticos e abióticos suficientes para que se mantenha em equilíbrio, que pode ser atingido por meio da reintrodução de espécies nativas no ambiente que se pretende recuperar (RODRIGUES et al., 2009).

As presenças de árvores geram uma série de benefícios ao solo e ambiente, como a proteção contra a erosão, aumento da matéria orgânica, conservação da água, aumento de organismos benéficos ao solo, menor proliferação de pragas e doenças, menor ocorrência de plantas invasoras, conservação da biodiversidade, fauna e flora, proteção contra queimadas e sendo assim, imita um ecossistema florestal (COSTA, 2015).

A degradação dos solos é um problema que influencia todo o mundo e constitui um fenômeno de grande importância, em razão da rapidez com que se processa e pelo fato de acarretar grandes prejuízos para diversas atividades econômicas e para o meio ambiente, dentre as técnicas mais utilizadas pelos agricultores destacam-se o desmatamento, as queimadas e o preparo do solo, expondo o solo aos fatores climáticos intensificando a degradação (EDUARDO et al., 2013; SILVA, 2012).

Segundo Bertoni \& Lombardi Neto (2010), a erosão hídrica é a forma mais ativa do processo de degradação dos solos, ela consiste de uma série de transferências de energia e matéria provocadas por um desequilíbrio do sistema água/solo/cobertura vegetal, que resultam 
na perda progressiva de solo (DEMARCHI et al., 2019). Em consequência desses danos, torna-se essencial a aplicação de técnicas que permitam a conservação do solo.

Variadas práticas são utilizadas para controlar a erosão hídrica em solos agrícolas, sendo normalmente divididas em práticas edáficas, vegetativas e mecânicas. As práticas mecânicas são aquelas nas quais são utilizadas estruturas artificiais para a redução da energia do escoamento da água, sendo o terraceamento a difundida e utilizada (GRIEBELER, 2005).

Terraços são estruturas compostas por um dique e um canal, dispostos no sentido transversal à declividade do terreno, formando obstáculos físicos para reduzir a velocidade do escoamento superficial e ordenar o movimento da água sobre a superfície do solo (MAGALHÃES, 2013). Tem como objetivo conter as águas do escoamento superficial, reduzindo a velocidade do escoamento, armazenando a água no solo o que contribui para o abastecimento do lençol freático e reduz o efeito de veranicos (DENARDIN et al., 2011).

Os terraços são utilizados com a finalidade de reduzir a erosão porque a vertente é dividida em segmentos relativamente curtos, evitando que o escoamento superficial alcance velocidades erosivas, quando adequadamente planejados e construídos, podem atender a outra finalidade, como: aumentar a capacidade de retenção de água pelo solo para o uso das culturas (OLIVEIRA, 2010).

Sistemas agroflorestais

Sistemas agroflorestais (SAFs) são considerados como modelo sustentável de uso da terra, formados pelo plantio de espécies lenhosas perenes (árvores e arbustos) que se desenvolvem consorciadas com plantas herbáceas (vegetais, pastagens) ou animais, num arranjo espacial ou rotação para se beneficiar dos resultados ecológicos. (MONTAGNINI, 2005; HARVEY et al., 2008; ASSIS, 2008).

A escolha das espécies para compor um SAF está diretamente relacionada com o tipo de manejo do sistema e sua função, na recuperação de áreas degradadas, estas devem apresentar características intrínsecas às áreas a serem recuperadas (BENDITO et al. 2018).

Mesclar produtos madeireiros e não madeireiros pode ser a melhor escolha para o sucesso do empreendimento, pois proporciona fluxo de caixa maior ao agricultor, flexibilidade de comercialização e otimização de mão-de-obra (BENDITO et al. 2017). 
Pau-d'arco (Handroanthus impetiginosus(Mart. ex DC.) Mattos)

Conhecida vulgarmente como pau d'arco, a espécie arbórea (Handroanthus impetiginosus (Mart. ex DC.) Mattos) cuja sinonímia é Tabebuia impetiginosa (Mart. ex DC.) tem origem nativa e pertence à família BIGNONIACEAE, podendo chegar a altura de 8 a 20 metros, com tronco de 60-90 cm de diâmetro,produz madeira de qualidade, tem importância econômica, medicinal, paisagística, e em programas de reflorestamento (SIQUEIRA FILHO et al., 2009).

Ocorre principalmente nos domínios fitogeográficos da Amazônia, Caatinga, Cerrado, Mata Atlântica e Pantanal, nas regiões Norte (Pará, Tocantins), Nordeste (Maranhão, Piauí, Ceará, Rio Grande do Norte, Paraíba, Pernambuco, Bahia, Alagoas, Sergipe), Centro-Oeste (Mato Grosso, Mato Grosso do Sul, Goiás e Distrito Federal) e Sudeste (Minas Gerais, Espírito Santo, Rio de Janeiro e São Paulo) (LORENZI, 1992; LOHMANN, 2012).

O pau d'arco (Handroanthus impetiginosus (Mart. ex DC.) Mattos) ocorre em locais com regime pluviométrico uniforme, porém aceita um déficit hídrico moderado, ocorre naturalmente em vários tipos de solo, cujos relevos podem ser desde planos a pouco ondulados, apresentado um melhor crescimento em solos com fertilidade química média a elevada, profundos, com boa drenagem (CARVALHO, 2003).

O desenvolvimento das mudas no campo é rápido, alcançando mais de 3,5 $\mathrm{m}$ aos dois anos (LORENZI, 1992). Devido à sua intensa exploração e por ser excelente para enriquecimento de capoeiras e vegetações empobrecidas é utilizada na recuperação de áreas degradadas (MAIA, 2004).

Rochagem

A Associação Nacional para a Difusão de Adubos (ANDA, 2018), relata a dependência do Brasil com relação à importação de fertilizantes. Dessa forma, é necessário encontrar mecanismos que possam diminuir esta dependência do mercado internacional. Com isso a tecnologia da rochagem pode-se configurar como excelente alternativa, uma vez que o Brasil é um país que possui diversidade de rochas que pode viabilizar o uso de diferentes tipos, em diferentes regiões para alcançar padrões de fertilidade compatíveis com as 
necessidades regionais e ainda facilitar mecanismos de desenvolvimento regional (LOPES, 2005).

A rochagem é uma prática que traz muitas vantagens para o desenvolvimento de diversas culturas na agricultura, quando comparada com fontes minerais altamente solúveis (THEODORO, et al., 2006), dentre as vantagens estão: não salinização do solo, a não absorção em excesso de potássio, assim beneficiando a absorção de cálcio e magnésio, menor lixiviação dos nutrientes, diminuição da fixação de fósforo solúvel pela presença de sílica, além da redução da mão de obra, pois com a aplicação do pó de rocha pode não haver necessidade frequente de adubar o solo, pois seu efeito é prolongado (AMPARO, 2003).

Para Theodoro et al. (2006) e Theodoro e Leonardos (2006) a viabilidade agronômica e econômica de fontes regionais de nutrientes do pó de rocha, também presente nos parques geológicos presentes na Chapada do Araripe, pode reduzir a ocorrência da agricultura migratória, sendo uma boa opção para os pequenos produtores, por serem mais acessíveis e de menor custo.

A região do Cariri cearense, constitui um importante polo mineral com a sua rica reserva de calcário laminado utilizado com pedra de revestimento sob o nome de "Pedra Cariri”, abrangendo principalmente os municípios de Santana do Cariri e Nova Olinda, esta atividade de exploração vem sendo desenvolvida há mais de 30 anos, gerando uma quantidade considerável de rejeitos (cerca de 70\%) (VIDAL; PADILHA; OLIVEIRA, 2015).

\section{Metodologia}

Caracterização da área de estudo

O experimento foi conduzido na cidade de Nova Olinda- CE na comunidade Triunfo $\left(7^{\circ} 08^{\prime} 47^{\prime \prime} \mathrm{S}\right.$ e $39^{\circ} 43^{\prime} 02^{\prime}$ W), conforme Figura 1 . O clima caracteriza-se como tropical quente 
semiárido, com temperatura média entre 24 e $26^{\circ} \mathrm{C}$ e pluviometria anual de $682,7 \mathrm{~mm}$ (IPECE,2017). Sua geologia é composta por rochas Pré-Cambrianas do embasamento cristalino (quartzitos, xistos, gnaisses e migmatitos). No extremo sul ocorrem rochas sedimentares da bacia do Araripe, representadas por arenitos da Formação Mauriti (EoCambriano) e calcários da Formação Santana (Mesozóico) (CPRM, 1998).

O relevo tem a forma suave ondulada (6\%) e pouco dissecada da depressão sertaneja, produto da superfície de aplainamento em atuação no Cenozóico. As altitudes ficam próximas dos 500 metros acima do nível do mar. A vegetação predominante é caatinga arbórea ou floresta caducifólia espinhosa, encontrando-se também manchas de mata seca (floresta subcaducifólia tropical) (CPRM, 1998).

Na localidade encontra-se solos classificados como Luvissolos (SiBCS, 2018), os quais compreendem solos com elevada fertilidade natural, dotados de argilas com alta capacidade de retenção de íons trocáveis (argila de atividade alta) e saturação por bases também alta (elevada capacidade de retenção de nutrientes) nos horizontes sub-superficiais, sendo que áreas expressivas são encontradas no nordeste brasileiro, onde se distribuem principalmente na zona semiárida (MANZATTO et al. 2002).

Precipitação em Nova Olinda

A precipitação verificada no município de Nova Olinda, posto Nova Olinda (FUNCEME, 2019), entre o período de plantio e a primeira leitura que totalizou $410 \mathrm{~mm}$. Verificou-se que no dia do plantio, 23 de março, choveu $13 \mathrm{~mm}$ e ocorreu déficit hídrico no período de 16 a 23 de abril com duração de 8 dias. 
Figura 1 - Mapa de localização do município

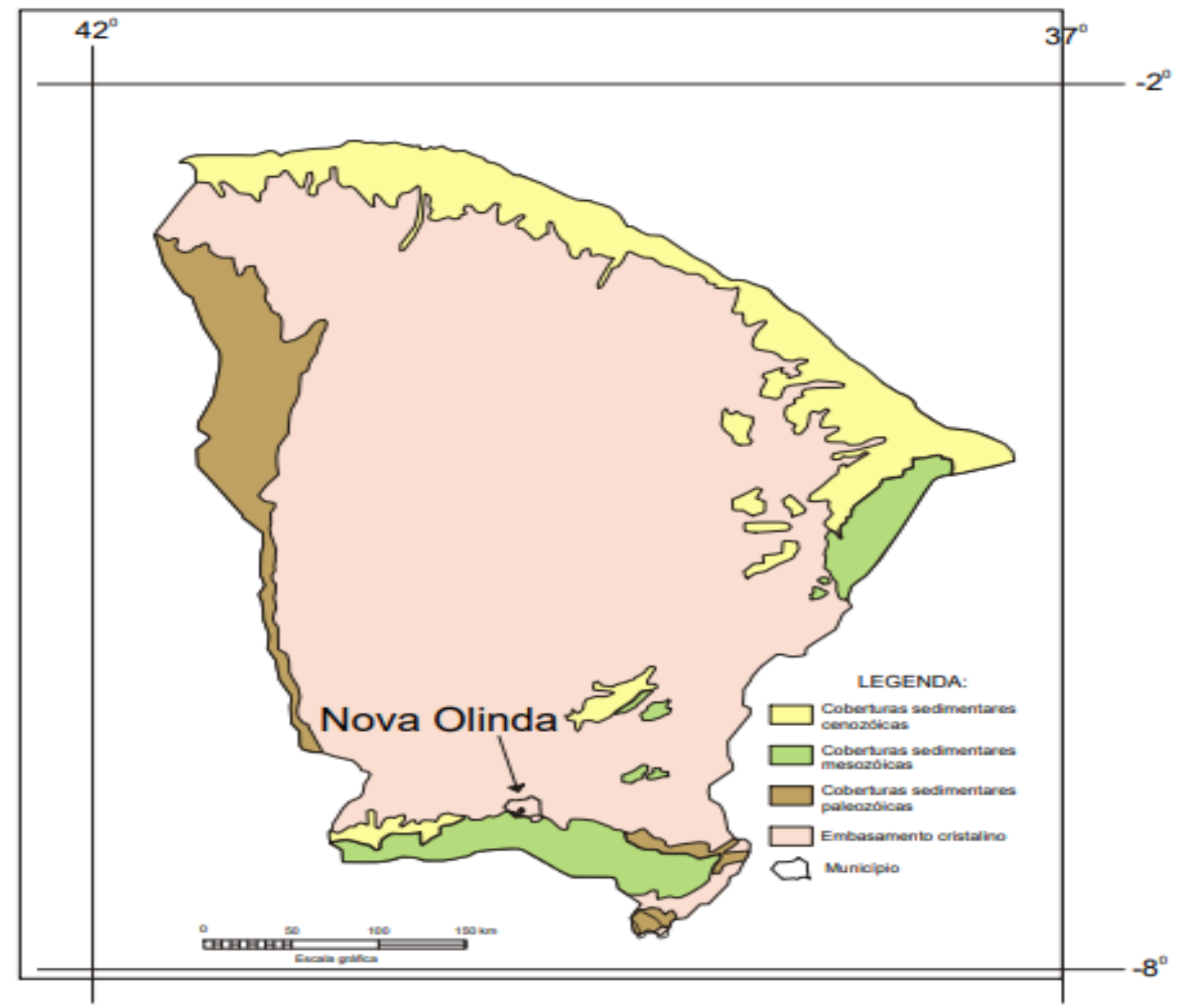

Fonte: CPRM (1998).

Participação dos agricultores

Foi realizada uma reunião no dia 13 de janeiro de 2019 com a Associação dos Criadores de Peixe de Triunfo (comunidade de Nova Olinda-CE) objetivando a sensibilização da pesquisa de recuperação de áreas degradadas e buscar a participação da comunidade.

Implantação e delineamento experimental

As sementes de pau d'arco utilizadas no experimento foram colhidas na safra de novembro de 2018, que foram semeadas em sacos plásticos de polietileno $(10 \mathrm{~cm}$ x $20 \mathrm{~cm}$ ), próprio para mudas contendo substrato, no dia 17 de fevereiro de 2019, pela associação dos 
criadores de peixe de Triunfo. As sementes emergiram 10 dias após a semeadura, permanecendo nos sacos até o dia 23 de março de 2019, totalizando 34 dias antes do plantio a campo.

Antes da instalação do experimento foi feito o terraceamento para construção de cada bloco (estações), o qual apresentou as seguintes dimensões: 0,30 m de largura, 0,30 m de profundidade, 0,30 m altura e $12 \mathrm{~m}$ de comprimento (Figuras 2 e 3). Os terraços foram distanciados um do outro em $20 \mathrm{~m}$, os quais foram posicionados na base de cada bloco. Eles foram construídos manualmente pelos próprios agricultores da associação, utilizando-se de enxada. Em seguida, o leito de semeadura foi preparado e adicionado o pó de rocha.

As mudas foram plantadas a campo no espaçamento de 5,5 metros entre plantas e 5,0 metros entre linhas (Figura 2) dispostas em delineamento experimental de blocos ao acaso, em cinco repetições, com cada unidade experimental composta por três plantas, totalizando 15 plantas por tratamento. Os tratamentos consistiram de uma testemunha (tratamento 1: T1), de $50 \mathrm{~g}$ do pó de rocha da pedra cariri amarelo (tratamento 2: T2), de 50g pó de rocha da pedra cinza (tratamento 3: T3) e de $25 \mathrm{~g}$ do pó de rocha da pedra cariri amarelo $+25 \mathrm{~g}$ do pó de rocha da pedra cariri cinza (tratamento 4: T4).

Figura 2 - Croqui da área

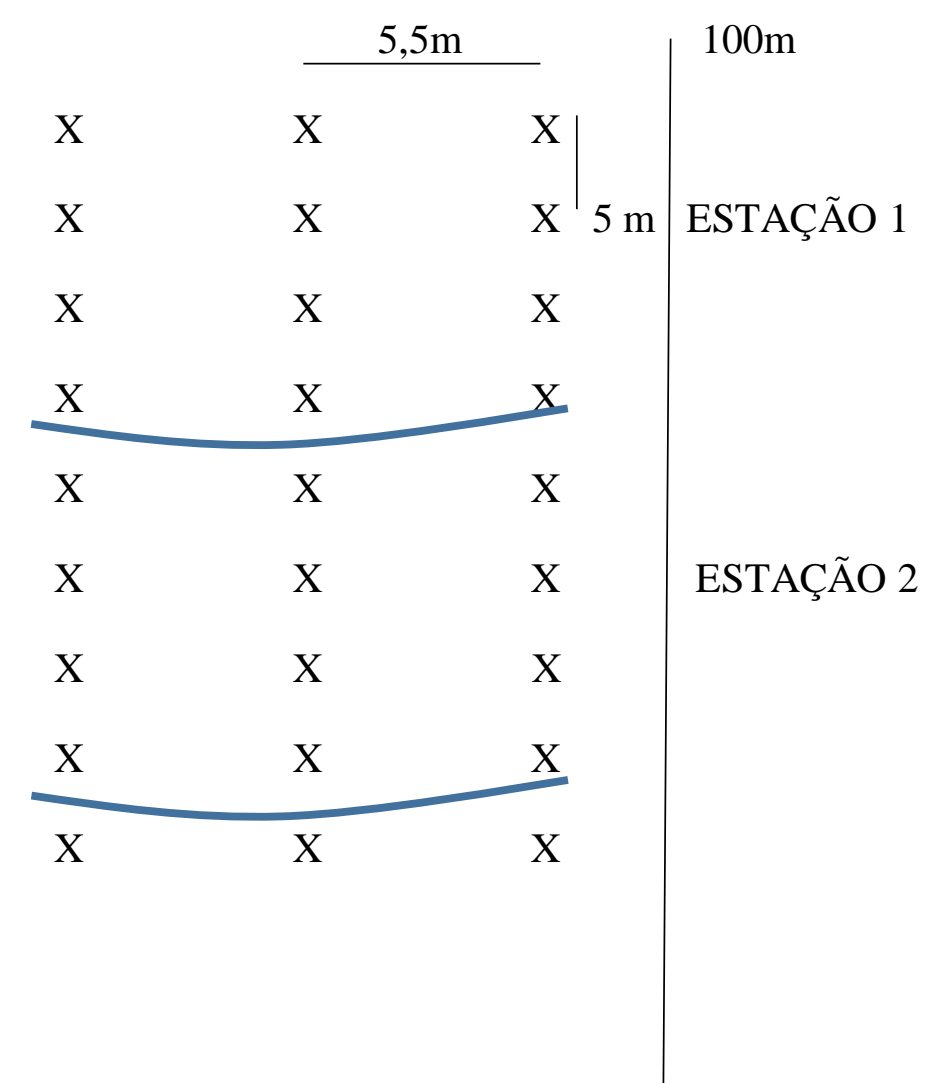




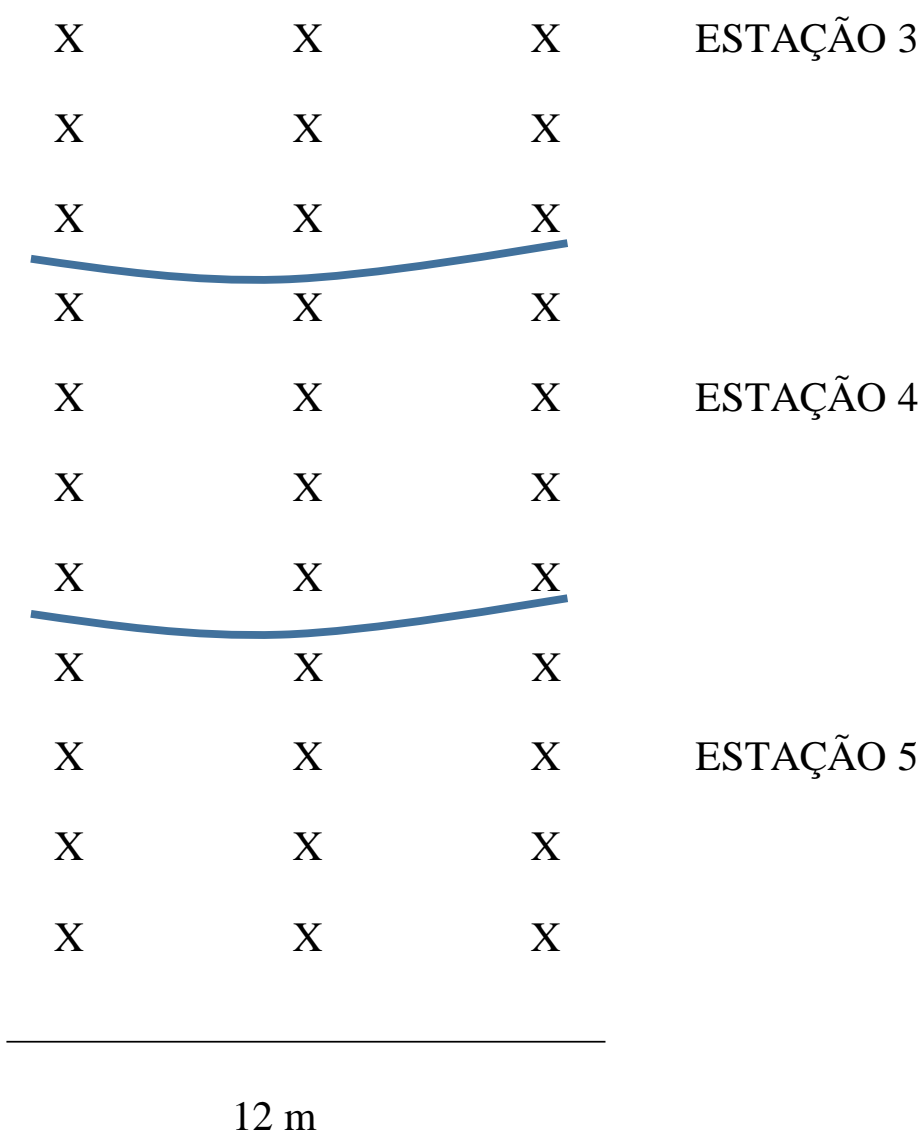

DECLIVE $6 \%$

Fonte: Elaborada pelo autor. 
Figura 3 - Terraços de base estreita
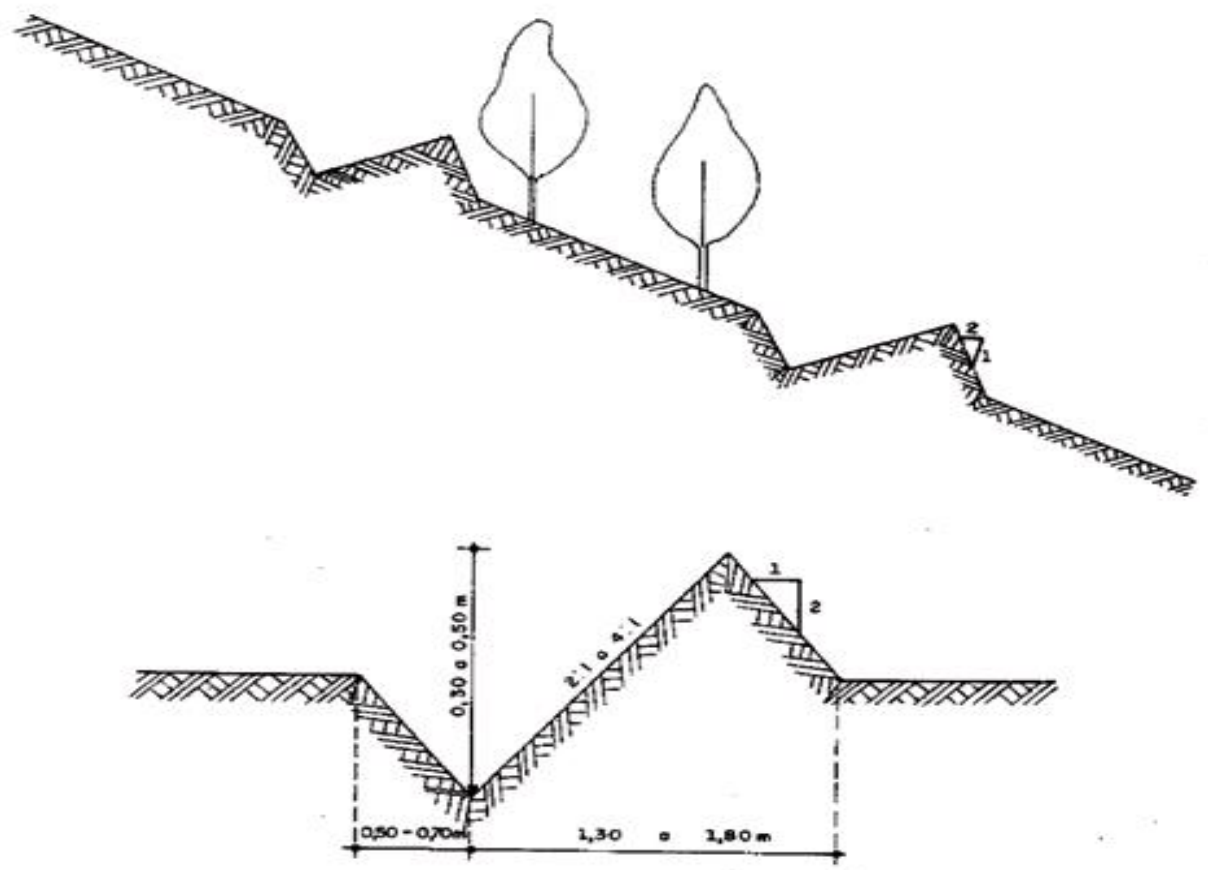

Fonte: Oliveira (2010)

Parâmetros de avaliação

Foram feitas avaliações com base na determinação da sobrevivência e crescimento do diâmetro do colo $(\mathrm{cm})$ no momento do transplante das mudas a campo, para servir de parâmetro de comparação nas avaliações seguintes.

As avaliações posteriores foram realizadas em 04 de maio e em 04 de junho do corrente ano, medindo em cada ocasião o diâmetro do caule $(\mathrm{cm})$ ao nível do solo, utilizandose um paquímetro digital.

Análise de dados

Os dados das avaliações referentes ao diâmetro do caule foram submetidos a análise de variância e as médias foram comparadas pelo teste de Tukey, ao nível de significância de $5 \%(<0,05)$ de probabilidade, utilizando o software SPSS Statistics (IBM, 2018). 


\section{Resultados e Discussão}

As médias do diâmetro inicial da base das mudas de pau d'arco encontram-se apresentadas na Figura 4. Observa-se que a estação 4 apresenta maior média, seguida da estação 3, e as estações 1, 2 e 5 apresentam médias similares.

Figura 4 - Bloxplot com as médias de diâmetros $(\mathrm{cm})$ iniciais no dia do plantio das mudas de pau d'arco.

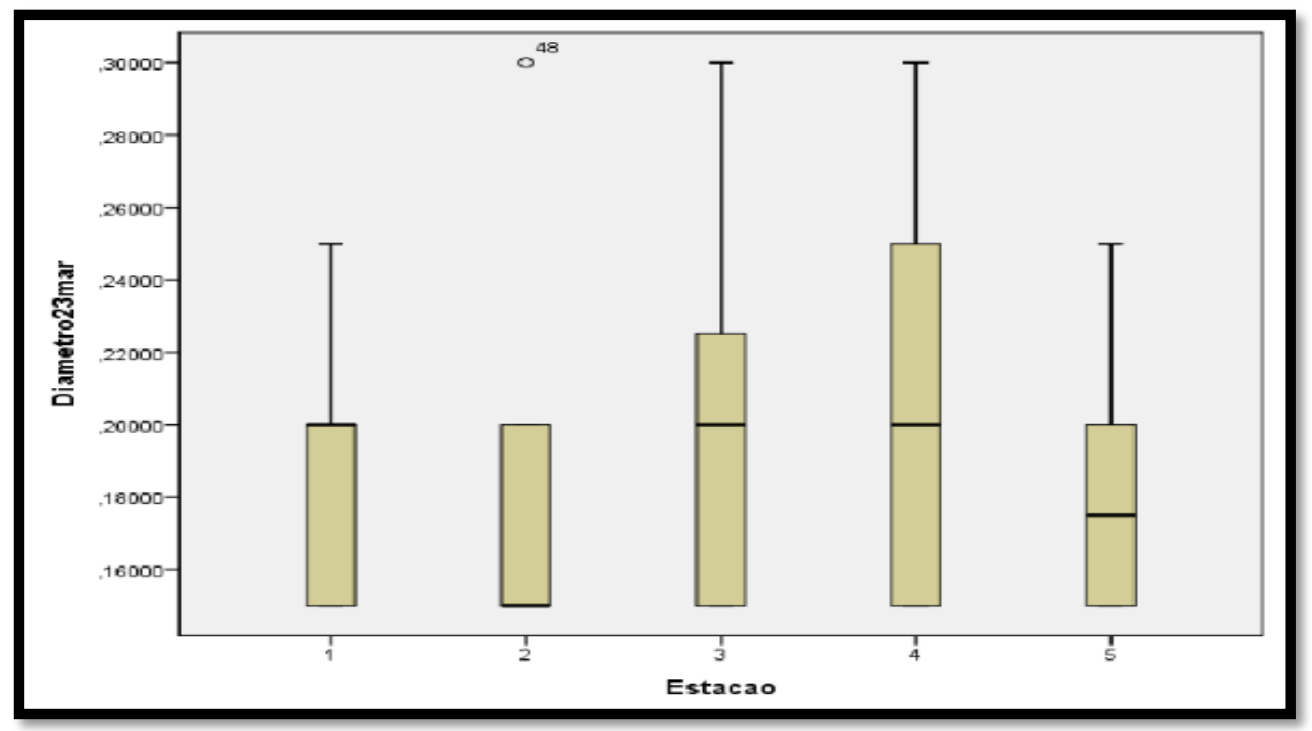

Fonte: IBM (2018).

\section{Terraceamento}

A primeira medição foi realizada no dia 04 de maio de 2019, e durante o período entre o plantio e a primeira medição o déficit hídrico provocou a morte de 7 plantas, sendo 2 na estação 1, 1 na estação 2, 3 na estação 4, e 1 na estação 5, provocando uma alteração na média dos diâmetros, conforme Figura 5. Entretanto a estação 3 não houve mortalidade em função do escoamento sub-superficial pela água acumulada nos terraços 1 e 2 posicionados mais acima, que proporcionou uma maior umidade, melhorando a qualidade ambiental nesta estação (Figura 6), conforme relatado também por Oliveira (2010). 


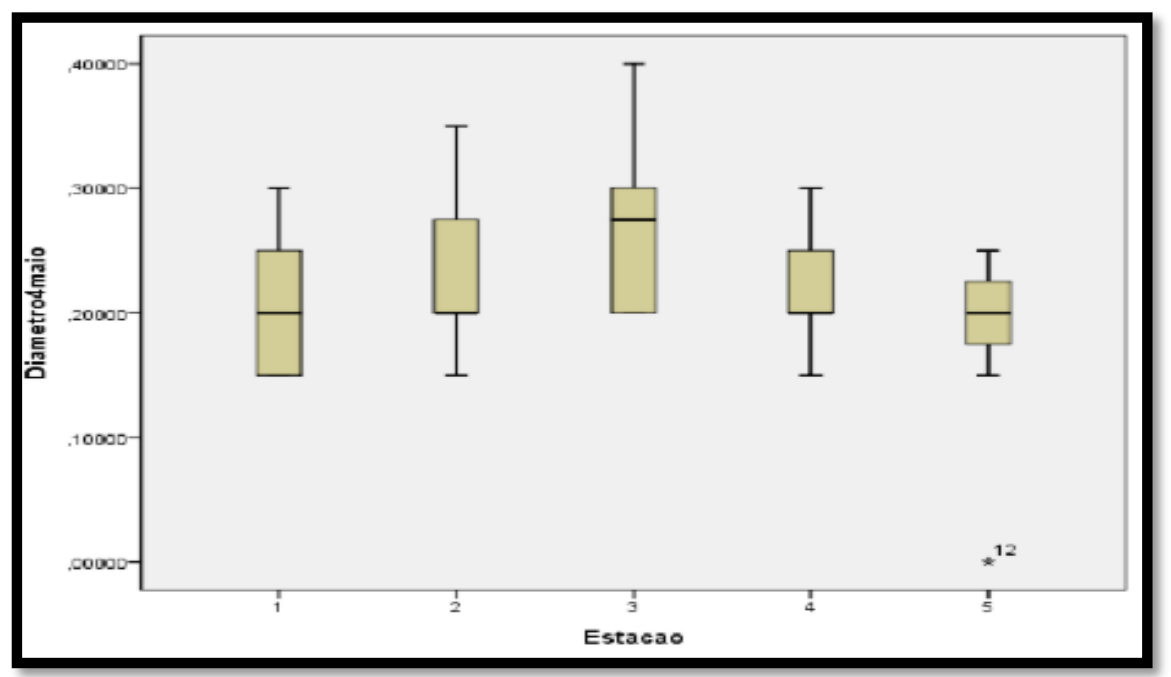

Figura 5 - Bloxplot para diâmetro médio $(\mathrm{cm})$ das plantas na primeira medição

Fonte: IBM (2018).

A taxa de crescimento nos diâmetros médios das plantas apresentou os seguintes valores: na estação $1-17 \%$, na estação 2- 22\%, na estação 3- 36\%, na estação $4-15 \%$ e na estação 5- 11\%, esses valores foram obtidos com a diferença das medições entre o plantio e a primeira medição. Esses percentuais podem ser justificados pelo maior acumulo de água na estação 3, conforme mencionado anteriormente.

Figura 6 - Terraço de base estreita com água de chuva

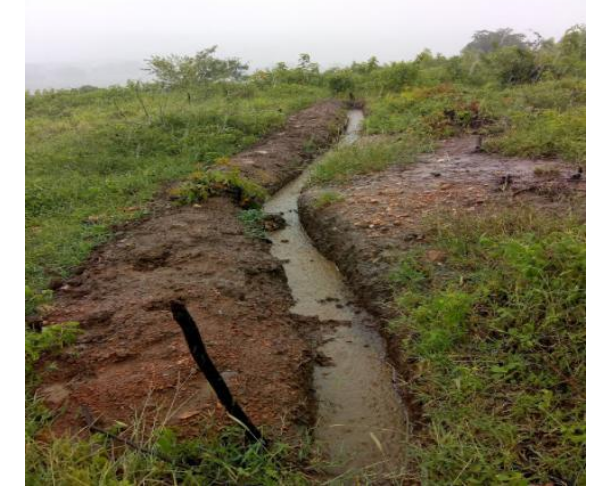

Fonte: Elaborada pelo autor.

A precipitação verificada no município de Nova Olinda, posto Nova Olinda (FUNCEME, 2019), entre o período da primeira medição 04 de maio e a segunda 04 de junho, 
totalizou $53 \mathrm{~mm}$. Verifica-se a ocorrência dos déficits hídricos no período de 3 a 16 de maio de 2019, com duração de 13 dias, e de 20 a 30 de maio de 2019, com duração de 10 dias, provocando uma alteração na média dos diâmetros, conforme Figura 7. Nesse período a taxa de crescimento nos diâmetros médios das plantas apresentou os seguintes valores: na estação 2- 4\%, na estação 3- 19\%, na estação $4-9 \%$, na estação 5- 5\% e na estação 1 não houve alteração, em comparação a avaliação anterior. Durante o período os déficits hídricos provocaram a morte de 3 plantas, sendo 2 na estação 1 , 1 na estação 2 .

A mortalidade que ocorreu nas estações 1 e 2 foi devido à falta de umidade, já nas estações 3, 4 e 5 não houveram mortalidades em função do maior acúmulo de água nos terraços 2, 3 e 4, proporcionado também pelo tempo de escoamento sub-superficial do solo, ocorrido devido as chuvas de março, abril e maio.

A deficiência hídrica é um fator limitante para o desenvolvimento das plantas, devido a irregularidade de chuvas, sendo necessário o uso de práticas que armazenem a água por um maior período, concordando com Malvezzi (2007).

Figura 7 - Bloxplot para diâmetro médio $(\mathrm{cm})$ das plantas na segunda medição 


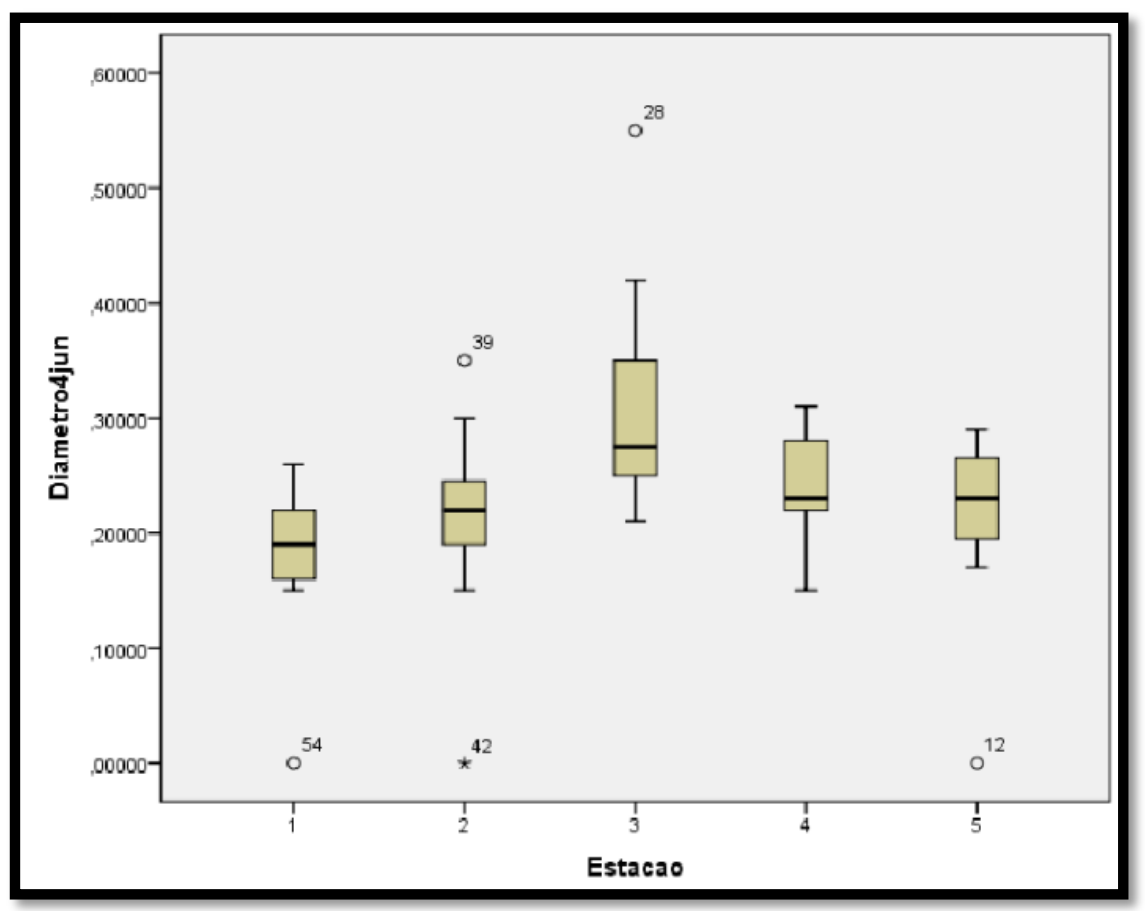

Fonte: IBM (2018)

Análise dos terraços

A análise de variância realizada para a taxa de crescimento (Tabela 1) e diâmetros das plantas (Tabela 2), entre o período de plantio e a segunda medição, indica que houve diferença significativa entre as estações 1 e 3 , o que pode ser verificado pela Figura 8.

Tabela 1 - Resumo da análise de variância para taxa de crescimento (\%)

\begin{tabular}{lcl}
\hline Fonte de variação & Graus de liberdades & Quadrados médios \\
\hline Estação & 4 & $2118,19 * *$ \\
Tratamento & 3 & $465,34 \mathrm{~ns}$ \\
Estação*tratamento & 12 & $201,27 \mathrm{~ns}$ \\
Erro & 40 & 285,71 \\
Total & 59 & \\
\hline
\end{tabular}

CV $(\%)=81,82$. Média geral: 20,66 
** significativo ao nível de $1 \%$ de probabilidade; ns: não significativo $(p<0,05)$

Entre as estações pode-se verificar a taxa crescimento entre o plantio e a segunda medição: estação 1- 17\%, estação 2- 35\%, estação 3- 63\%, estação 4- $26 \%$ e estação 5- 27\%. A estação 1 apresentou a menor taxa de crescimento, indicando que houve erosão hídrica de solo e lixiviação de nutrientes. O escoamento superficial provocou a perda de água da estação 1 e proporcionou esse menor desempenho no crescimento das plantas, corroborado por Dermachi et al. (2019).

Tabela 2 - Resumo da análise de variância para diâmetro $(\mathrm{cm})$ da base do caule

\begin{tabular}{lcl}
\hline Fonte de variação & Graus de liberdades & Quadrados médios \\
\hline Estação & 4 & $0,052^{* *}$ \\
Tratamento & 3 & $0,003^{\mathrm{ns}}$ \\
Estação*tratamento & 12 & $0,012^{\mathrm{ns}}$ \\
Erro & 40 & 0,011 \\
Total & 59 & \\
\hline
\end{tabular}

CV $(\%)=49,20$. Média geral: 0,2078

** significativo ao nível de $1 \%$ de probabilidade; ns: não significativo $(p<0,05)$

Os terraços demonstraram capacidade de reter água do escoamento superficial, armazenando nas estações, em especial a estação 3, reduzindo o efeito de veranicos concordando com Denardin et al. (2011).

O uso de espécies nativas é de extrema importância na recuperação de áreas degradadas, visto que essas apresentam características particulares às áreas a serem recuperadas, se estabelecendo melhor na área, concordando com Bendito et al. (2018).

Figura 8 - Comparação de estações pelo Teste de Kruskal-Wallis 


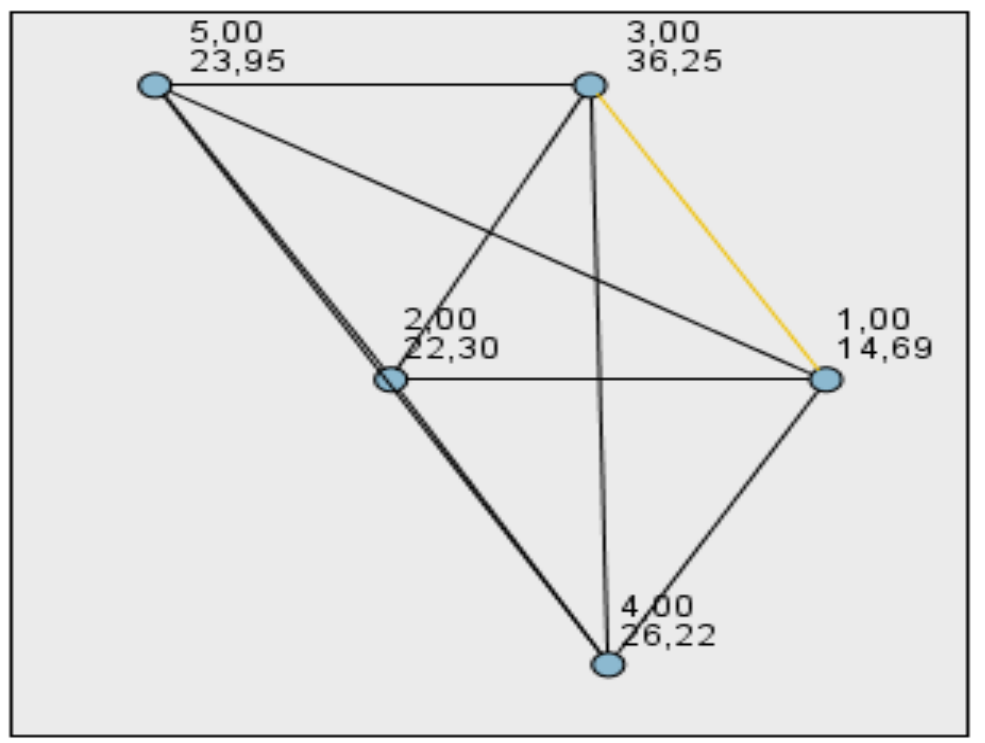

de amostras independentes

Fonte: IBM (2018).

A análise entre os terraços pelo teste de Kruskal-Wallis considerou amostras de tamanhos diferentes em função da mortalidade das plantas, que para o efeito de recuperação de áreas degradadas tem que ser levado em consideração. A mortalidade no terraço 1 poderia ter sido minimizada com a construção de um terraço no início da vertente.

Os terraços de base estreita contribuíram para minimizar a erosão, além de seus efeitos degradantes na área estudada, além de aumentar a disponibilidade de umidade para as plantas, reduzindo os efeitos dos déficits hídricos e aumentando a qualidade ambiental, conforme afirma Magalhães (2013).

Análise do pó de rocha

O crescimento do diâmetro do caule das plantas (Tabela 3) e a taxa de crescimento (Tabela 4) em função da aplicação do pó de rocha, não apresentaram diferença significativa.

Observa-se que na estação 3, onde houve maior umidade no período, o material que mais se superou foi o pó de rocha cinza $(0,380 \mathrm{~cm})$, nas estações 4 e 5 , onde houveram menor umidade, a testemunha se sobressaiu, indicando que o pó de rocha necessita de umidade para que haja as reações químicas necessária para a liberação dos nutrientes. Como não houve 
umidade suficiente, visto que o plantio foi de sequeiro, o resultado obtido não foi conforme Theodoro et al. (2006) e Theodoro e Leonardos (2006).

Tabela 3 - Médias dos efeitos principais de tratamento e estação para diâmetro $(\mathrm{cm})$ do caule do Handroanthus impetiginosus (Mart. ex DC.) Mattos)

\begin{tabular}{clllll}
\hline \multirow{2}{*}{ Estação } & \multicolumn{3}{c}{ Tratamento } & Médias \\
\cline { 2 - 5 } & Testemunha & $\begin{array}{l}\text { Pó de rocha } \\
\text { amarelo }\end{array}$ & $\begin{array}{l}\text { Pó de rocha } \\
\text { cinza }\end{array}$ & $\begin{array}{l}\text { Pó de rocha amarelo } \\
\text { mais cinza }\end{array}$ & \\
\hline 1 & 0,063 & 0,123 & 0,187 & 0,160 & $0,133 \mathrm{~b}$ \\
2 & 0,170 & 0,153 & 0,227 & 0,227 & $0,194 \mathrm{ab}$ \\
3 & 0,317 & 0,240 & 0,380 & 0,310 & $0,312 \mathrm{a}$ \\
4 & 0,270 & 0,227 & 0,067 & 0,163 & $0,182 \mathrm{~b}$ \\
5 & 0,240 & 0,187 & 0,180 & 0,226 & $0,213 \mathrm{ab}$ \\
\hline Médias & 0,212 & 0,186 & 0,208 & 0,221 &
\end{tabular}

Médias seguidas pela mesma letra, na coluna, e ausência de letra nas linhas, não difere entre si pelo teste Tukey a $5 \%$ de significância.

A testemunha da estação 1 foi a que teve menor crescimento, indicando que a erosão hídrica e os déficits hídricos influenciaram no baixo crescimento das plantas, conforme afirmam Denardin et al. (2011). Em anos de melhor distribuição pluviométrica o pó de rocha poderá proporcionar melhor desenvolvimento às plantas, pois seu efeito é prolongado conforme afirma Amparo (2003).

Tabela 4 - Média percentual (\%) das interações e efeitos principais da estação e tratamento do diâmetro (cm) do caule de H. impetiginosus (Mart. ex DC.) Mattos)

\begin{tabular}{cllllll}
\hline \multirow{2}{*}{ Estação } & \multicolumn{3}{c}{ Tratamento } & Médias \\
\cline { 2 - 5 } & Testemunha & $\begin{array}{l}\text { Pó de rocha } \\
\text { amarelo }\end{array}$ & $\begin{array}{l}\text { Pó de rocha } \\
\text { cinza }\end{array}$ & $\begin{array}{l}\text { Pó de rocha amarelo } \\
\text { mais cinza }\end{array}$ & \\
\hline 1 & 7,843 & 3,33 & 8,89 & 4,66 & $6,18 \mathrm{~b}$ \\
2 & 10,00 & 35,00 & 28,33 & 20,95 & $19,40 \mathrm{ab}$
\end{tabular}




\begin{tabular}{rrrrrl}
3 & 35,55 & 36,66 & 58,61 & 37,22 & $42,01 \mathrm{a}$ \\
4 & 23,44 & 20,00 & 8,33 & 6,00 & $14,44 \quad \mathrm{~b}$ \\
5 & 18,66 & 13,33 & 40,00 & 13,00 & $21,25 \mathrm{ab}$ \\
\hline Médias & 19,10 & 21,66 & 28,83 & 16,36 &
\end{tabular}

Médias seguidas pela mesma letra, na coluna, e ausência de letra nas linhas, não difere entre si pelo teste Tukey a 5\% de significância.

A taxa de crescimento do tratamento $3(58,61 \%)$ na estação 3 , apesar de não ter apresentado diferença significativa entre os demais tratamentos, indica que o pó de rocha cinza apresentou melhor resultado em termos de valores absolutos. Conforme os dados dos dois pós de rocha utilizados (Tabela 5) observa-se que o pó de rocha cinza apresenta menor $\mathrm{pH}$, menor condutividade elétrica, que pode ter influenciado no resultado.

Tabela 5- Análise química dos pós de rocha

\begin{tabular}{|c|c|c|c|c|c|c|c|c|c|c|c|c|}
\hline $\begin{array}{l}\text { Nutrientes/ } \\
\text { material }\end{array}$ & $\begin{array}{c}P \\
\mathrm{~g} / \mathrm{kg}\end{array}$ & $\begin{array}{l}\mathbf{P}_{2} \mathrm{O}_{5} \\
\mathrm{~g} / \mathrm{kg}\end{array}$ & $\begin{array}{c}\mathrm{K}^{+} \\
\mathrm{g} / \mathrm{kg}\end{array}$ & $\begin{array}{l}\mathrm{K}_{2} \mathrm{O} \\
\mathrm{g} / \mathrm{kg}\end{array}$ & $\begin{array}{l}\mathrm{Ca}^{2+} \\
\mathrm{g} / \mathrm{kg}\end{array}$ & $\begin{array}{l}\mathrm{Mg}^{2+} \\
\mathrm{g} / \mathrm{kg}\end{array}$ & $\begin{array}{c}\mathrm{S} \\
\mathrm{g} / \mathrm{kg}\end{array}$ & $\begin{array}{l}\mathrm{Na}^{+} \\
\mathrm{g} / \mathrm{kg}\end{array}$ & $\begin{array}{c}\mathrm{N} \\
\mathrm{g} / \mathrm{kg}\end{array}$ & $\begin{array}{c}\text { B } \\
\mathrm{mg} / \mathrm{kg}\end{array}$ & pH & $\begin{array}{c}C E \\
d S / m\end{array}$ \\
\hline $\begin{array}{l}\text { Pó de } \\
\text { rocha }\end{array}$ & 0,07 & 0,17 & 0,02 & 0,03 & 36,20 & 1,20 & 7,75 & 0,40 & 0,56 & 1,4 & 8,2 & 4,21 \\
\hline Amarelo & & & & & & & & & & & & \\
\hline $\begin{array}{l}\text { Pó de } \\
\text { rocha } \\
\text { cinza }\end{array}$ & 0,02 & 0,04 & 0,02 & 0,03 & 35,80 & 1,08 & 2,24 & 0,40 & 0,28 & 1,08 & 7,8 & 1,75 \\
\hline
\end{tabular}

Fonte: Elaborada pelo autor.

A fertilidade natural do Luvissolo, conforme afirma Manzatto et al. (2002) e SiBCS (2018), também pode ter influenciado no resultado de modo a não ter diferenças significativas entre os diferentes tipos dos pós de rocha, pelo menos no período inicial de crescimento das plantas, visto que tais produtos são de liberação e dissolução lenta. Portanto, mesmo os produtos aplicados apresentarem elevada concentração de nutrientes (Tabela 5), não foi possível uma diferença significativa nos parâmetros avaliados para os tratamentos aplicados. 


\section{Conclusões}

Até o momento o uso de técnicas conservacionistas como o de terraços de base estreita apresentou-se satisfatório na melhoria das condições ambientais e influenciou na capacidade física dos solos degradados.

A dosagem dos diferentes pós de rocha em Luvissolo não foram suficientes para incrementarem o crescimento inicial das plantas.

\section{Referências}

ANDA, Associação Nacional para a Difusão de Adubos. Anuário estatístico 2018. Disponível em: <http://anda.org.br/?mpg=03.00.00\&ver=por> Acesso em: 09 jun 2019.

ASSIS, Luiz Alberto Guimarães. Doenças fúngicas em espécies florestais nativas na Amazônia Central. Manaus: INPA, 2008. Dissertação. (Mestrado em Ciências de Florestas Tropicais [CFT]), Instituto Nacional de Pesquisas da Amazônia, 2008.

AMPARO, A. Farinha de Rocha e biomassa. Agroecologia hoje. Botucatu, n.20, p. 10-12, 2003.

BENDITO, Bianca Pietsch Cunha et al. DIAGNÓSTICO AMBIENTAL E PROPOSIÇÃO DE USO DE SAF PARA ÁREA DE PASTAGEM DEGRADADA. Geoambiente On-Line, n. 29, 2017.

BENDITO, B.; SOUZA, P.; PEREIRA, M.; GONÇALVES, D. DIAGNÓSTICO AMBIENTAL E PROPOSIÇÃO DE USO DE SAF PARA ÁREA DE PASTAGEM DEGRADADA. Geoambiente On-line, n. 29, 2018.

BERTONI, J.; LOMBARDI NETO, F. Conservação do solo. 7.ed. São Paulo, Ícone, p. 355, 2010.

CALDEIRA, M. V. W; ROSA, G. N; FENILli, T. A. B; HARBS, R. M. P. Composto orgânico na produção de mudas de aroeira-vermelha. Scientia Agraria, v. 9, p. 27- 33, 2008. 
CARVALHO, P. E. R. Espécies arbóreas brasileiras. Empresa Brasileira de Pesquisa Agropecuária-EMBRAPA, Centro nacional de Pesquisa de Florestas- CNPF, 2003.

Companhia de Pesquisa de Recursos Minerais- CPRM. Disponível em <http://rigeo.cprm.gov.br/xmlui/bitstream/handle/doc/16607/Rel_Nova\%20Olinda.pdf?seque

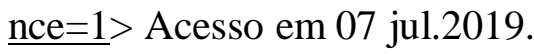

CURY, R. T. S.; CARVALHO JR. O. Manual para restauração florestal: florestas de transição. Série boas práticas 5. Canarana-MT: IPAM, 2011.

DEMARCHI, J. C.; PIROLI, E.L.; ZIMBACK, C.R.L. Estimativa de perda de solos por erosão na bacia hidrográfica do ribeirão das perobas (sp) nos anos 1962 e 2011 . Raega-O Espaço Geográfico em Análise, v. 46, n. 1, p. 02, 2019.

DENARDIN, J.E. et al. Sistema plantio direto: evolução e implementação. In: PIRES, J.L.M. et al. Trigo no Brasil: bases para produção competitiva e sustentável. Passo Fundo: Embrapa Trigo, cap.7, p. 185-215, 2011.

EDUARDO, Eliete Nazaré et al. Erodibilidade, fatores cobertura e manejo e práticas conservacionistas em Argissolo Vermelho-Amarelo, sob condições de chuva natural. Revista Brasileira de Ciência do Solo, v. 37, n. 3, 2013. Disponível em: $<$ https://www.redalyc.org/articulo.oa?id=180227932026 $>$. Acesso em 8 de abril de 2019.

EMPRESA BRASILEIRA DE PESQUISA AGROPECUÁRIA - EMBRAPA. Sistema brasileiro de classificação de solos. 5.ed. Brasília, 2018.

FERNANDES, F. R. C.; LUZ, A. B.; CASTILHOS, Z. C. Agrominerais para o Brasil. CETEM/MCT, 2010.

FUNCEME- Fundação Cearense de Meteorologia e Recursos Hídricos. Disponível em: <http://www.funceme.br/> Acesso em 08 jul 2019. 
GONÇALVES DOS SANTOS, H. Paulo Klinger Tito J, dos Anjos LHC, de Oliveira VÁ, Lumbreras JF, Coelho MR, et al. Sistema Brasileiro de Classificação de Solos (SiBCS). $5^{\text {a }}$ edição. Brasil: Empresa Brasileira de Pesquisa Agropecuária (Embrapa); 2018.

GONZAGA, T. W. C.; MATA, M. E. R. M.; SILVA H.; DUARTE, M. E. M. Crioconservação de sementes de aroeira (Astronium urundeuva Engl.), e baraúna (Schinopsis brasiliensis Engl.). Revista Brasileira de Produtos Agroindustriais, Campina Grande, v. 5, n. 2, p. 145-154, 2003.

GRIEBELER, Nori Paulo et al. Modelo para o dimensionamento e a locação de sistemas de terraceamento em nível. 2005.

GRIEBELER, Nori Paulo; CARVAlHO, D. F.; MATOS, A.T. Estimativa do custo de implantação de sistema de terraceamento, utilizando-se o sistema de informações geográficas. Estudo de caso: Bacia do Rio Caxangá, PR. Revista Brasileira de Engenharia Agrícola e Ambiental, v. 4, n. 2, p. 299-303, 2000.

HARVEY, C.A,; KOMAR, O.; CHAZDON, R.; FERGUSON, B. G.; FINEGAN, B.; GRIFFITH, D.M.; MARTÍNEZ-RAMOS, M.; MORALES, H.; NIGH, R.; SOTO-PINTO, L. Integrating Agricultural Landscapes with Biodiversity Conservation in the Mesoamerican Hotspot. Conservation Biology, v.22, n. 1, p. 8-15. 2008.

IBM SPSS Statistics 21. IBM. 2018. Software. Disponível em: <https://www.ibm.com/products/software> Acesso em 08 jul 2019.

IPCE, $2017 \quad$ Disponível em https://www.ipece.ce.gov.br/wpcontent/uploads/sites/45/2018/09/NovaOlinda2017.pdf

KAGEYAMA, P. Y.; OLIVEIRA, R. E.; MORAES, L. F. D.; ENGEL, V. L.; GANDARA, F. B. Restauração ecológica de ecossistemas naturais. Botucatu-SP: FEPAF, 2003. LIMA, M.A. Planejamento Urbano: SIG, avaliação socioeconômica e ecológica. In: Economia do Meio Ambiente. Ademar Ribeiro Romeiro, Bastiaan P. Reydon e Maria Lúcia A. Leonardi (org.) Campinas: UNICAMP, 1997. 
LIMA, J. R. L.; MARCATTO, C. ; SOUZA, E. F. F.; BRONZATTO, L. A. ; NASCIMENTO M. P. R. (Coord.). Programa de ação nacional de combate à desertificação e mitigação dos efeitos da seca - PAN BRASIL. Brasília - DF: Ministério do Meio Ambiente / Secretaria de Recursos Hídricos, 2004.

LOPES, A. S. Reservas de minerais potássicos e produção de fertilizantes potássicos no Brasil. Potássio na agricultura brasileira. Piracicaba: Potafos, p. 21-32, 2005.

LORENZI, H. Árvores Brasileiras: Manual de identificação e cultivo de plantas arbóreas nativas do Brasil. Nova Odessa: Plantarum, 1992.

LOHMANN, L. G. Bignoniaceae in Lista de Espécies da Flora do Brasil. Jardim Botânico do Rio de Janeiro. 2012. Disponível em: 〈http://floradobrasil.jbrj.gov.br/2012/FB11409>. Acesso em: 07 mai. 2019.

MAGALHÃES, G. M. F. Análise da eficiência de terraços de retenção em sub-bacias hidrográficas do Rio São Francisco. Revista Brasileira de Engenharia Agrícola e Ambiental, v.17, n.10, p.1109-1115, 2013. Disponível em: <http://dx.doi.org/10.1590/S1415-43662013001000013> acesso em 08/04/2019

MAIA, G.N. Caatinga: árvores e arbustos e suas utilidades. São Paulo: D\&Z Computação, 2004.

MALVEZZI, Roberto. Semiárido - uma visão holística. Brasília: Ed. Confea, 2007.

MANZATTO, Celso Vainer; FREITAS JUNIOR, Elias de; PERES, José Roberto Rodrigues. Uso agrícola dos solos brasileiros. Rio de Janeiro: Embrapa Solos, 2002.

MONTAGNINI, F. Environmental services of agroforestry systems. First World Congress on Agroforestry, Orlando, Florida, USA, 27 June-2 July 2004. Journal of Sustainable Forestry, 2005 . 
OLIVEIRA, J. B. Práticas inovadoras de controle edáfico e hidroambiental para o semiárido do Ceará. Fortaleza: Secretaria de Recursos Hídricos- PRODHAM,p.190, 2010.

RODRIGUES, R.R.; BRANCALION, P.H.S.; ISERNHAGEN, I. Pacto pela restauração da Mata Atlântica: referencial dos conceitos e ações de restauração florestal. São Paulo: LERF/ESALQ. Instituto BioAtlântica, 2009.

SÁNCHEZ, Luis Enrique. Recuperação de Áreas Degradadas: Um campo multidisciplinar de pesquisas. In: Seminário Unesp. Rio Claro, 2006.

SIQUEIRA FILHO, José Alves de et al. Guia de campo de árvores da Caatinga. Petrolina: Franciscana, 2009.

SILVA, Dalva Damiana Estevam da. Avaliação da degradação ambiental a partir da prática da cultura do feijão no município de Tavares - PB, 2012.

SILVA, Roberto Marinho Alves da. Entre o Combate à Seca e a Convivência com o Semiárido: Transições Paradigmáticas e sustentabilidade do desenvolvimento. Tese (Doutorado). Centro de Desenvolvimento Sustentável. Brasília: Universidade de Brasília, 2006.

THEODORO, S. H. et al. Experiências de uso de rochas silicáticas como fonte de nutrientes. Espaço \& Geografia, Brasília, v. 9, n. 2, p. 263-292, 2006.

THEODORO, S. H.; LEONARDOS, O. H. The use of rocks to improve family agriculture in Brazil. Anais da Academia Brasileira de Ciências, Rio de Janeiro, v. 78, n. 4, p. 721-730, 2006.

VALCARCEL, ARICARDO; SILVA, ZILANDA DE SOUZA. A eficiência conservacionista de medidas de recuperação de áreas degradadas: proposta metodológica. Floresta, v. 27, n. 1, 1997. 
VIDAL, Francisco Wilson Hollanda; PADILHA, Manoel William Montenegro; OLIVEIRA, R. R. Aspectos geológicos da Bacia do Araripe e do aproveitamento dos rejeitos da Pedra Cariri-Ceará. Artigo apresentado no V Simpósio de Rochas Ornamentais do Nordeste, Recife, p. 31-36, 2005.

ZUFFO, Alan Mario. As regiões Semiáridas e suas Especialidades 2. Editora Atena. Ponta Grossa (PR), 2019. 